\title{
Cyclic admissible contraction and applications to functional equations in dynamic programming
}

\author{
Huseyin Isik', Bessem Samet ${ }^{2 *}$ and Calogero Vetro ${ }^{3}$
}

${ }^{*}$ Correspondence:

bsamet@ksu.edu.sa

2 Department of Mathematics,

College of Science, King Saud

University, P.O. Box 2455, Riyadh,

11451, Saudi Arabia

Full list of author information is

available at the end of the article

\begin{abstract}
In this paper, we introduce the notion of $T$-cyclic $(\alpha, \beta)$-contraction and give some common fixed point results for this type of contractions. The presented theorems extend, generalize, and improve many existing results in the literature. Several examples and applications to functional equations arising in dynamic programming are also given in order to illustrate the effectiveness of the obtained results.
\end{abstract}

MSC: Primary 47H10; secondary 54H25;65Q20

Keywords: common fixed point; point of coincidence; $T$-cyclic $(\alpha, \beta)$-admissible mapping; weakly compatible mappings; functional equations

\section{Introduction and preliminaries}

Fixed point theorems play a crucial role to constructing methods for solving problems in applied mathematics and the majority of other sciences. Thus, a large number of mathematicians have focused on this interesting topic. The Banach contraction mapping principle [1] is one of the pivotal results in fixed point theory. It is widely considered as the source of metric fixed point theory. Also its significance lies in its vast applicability in a number of branches of mathematics.

A new category of contractive fixed point problems was addressed by Khan et al. [2]. In this study they introduced the notion of altering distance function which is a control function that alters distance between two points in a metric space. This function and its extensions have been used in several problems of fixed point theory, some of which are noted in [3-6].

Definition $1([2])$ A function $\varphi:[0, \infty) \rightarrow[0, \infty)$ is called an altering distance function if the following properties are satisfied:

(i) $\varphi$ is nondecreasing and continuous,

(ii) $\varphi(t)=0$ if and only if $t=0$.

Recently, Samet et al. [7] presented the notions of $\alpha$ - $\psi$-contractive and $\alpha$-admissible mappings. The results obtained by Samet et al. [7] extended and generalized many existing fixed point results in the literature, in particular the Banach contraction principle. After

(c) 2015 Isik et al. This article is distributed under the terms of the Creative Commons Attribution 4.0 International License (http://creativecommons.org/licenses/by/4.0/), which permits unrestricted use, distribution, and reproduction in any medium, provided you give appropriate credit to the original author(s) and the source, provide a link to the Creative Commons license, and indicate if changes were made. 
that, several authors considered the generalizations of this new approach (see [8-13]). Very recently, Alizadeh et al. [12] offered the concept of a cyclic $(\alpha, \beta)$-admissible mapping and proved some new fixed point results which generalize and modify some recent results in the literature.

Definition 2 ([12]) Let $f: X \rightarrow X$ and $\alpha, \beta: X \rightarrow[0, \infty)$. We say that $f$ is a cyclic $(\alpha, \beta)$ admissible mapping if

(i) $\alpha(x) \geq 1$ for some $x \in X$ implies $\beta(f x) \geq 1$;

(ii) $\beta(x) \geq 1$ for some $x \in X$ implies $\alpha(f x) \geq 1$.

The purpose of this paper is to formulate the above definition in terms of two mappings so that we can prove existence and uniqueness of common fixed points for these mappings on a complete metric space. Our results improve and extend the results of [7, $12,14]$ and many others. Several examples and interesting consequences of our theorems are also given. As a consequence of the presented results, we discuss the existence and uniqueness of the common bounded solution of a functional equation arising in dynamic programming.

Definition 3 ([15]) Let $X$ be a nonempty set and $f, T: X \rightarrow X$. The pair $(f, T)$ is said to be weakly compatible if $f$ and $T$ commute at their coincidence points (i.e. $f T x=T f x$ whenever $f x=T x$ ). A point $y \in X$ is called a point of coincidence of $f$ and $T$ if there exists a point $x \in X$ such that $y=f x=T x$.

Following the direction in [10], we denote by $\Psi$ the family of all functions $\psi: \mathbb{R}_{+}^{4} \rightarrow \mathbb{R}_{+}$ such that:

$\left(\psi_{1}\right) \psi$ is nondecreasing in each coordinate and continuous;

$\left(\psi_{2}\right) \psi(t, t, t, t) \leq t, \psi(t, 0,0, t) \leq t$ and $\psi\left(0,0, t, \frac{t}{2}\right) \leq t$ for all $t>0$;

$\left(\psi_{3}\right) \psi\left(t_{1}, t_{2}, t_{3}, t_{4}\right)=0$ if and only if $t_{1}=t_{2}=t_{3}=t_{4}=0$.

\section{Main results}

Before proceeding with our results, let us give the following definitions which will be used efficiently in the proof of main results.

Definition 4 Let $f, T: X \rightarrow X$ and $\alpha, \beta: X \rightarrow[0, \infty)$. We say that $f$ is a $T$-cyclic $(\alpha, \beta)$ admissible mapping if

(i) $\alpha(T x) \geq 1$ for some $x \in X$ implies $\beta(f x) \geq 1$;

(ii) $\beta(T x) \geq 1$ for some $x \in X$ implies $\alpha(f x) \geq 1$.

Example 1 Let $f, T: \mathbb{R} \rightarrow \mathbb{R}$ be defined by $f x=x$ and $T x=-x$. Suppose that $\alpha, \beta: \mathbb{R} \rightarrow \mathbb{R}^{+}$ are given by $\alpha(x)=e^{-x}$ for all $x \in \mathbb{R}$ and $\beta(y)=e^{y}$ for all $y \in \mathbb{R}$. Then $f$ is a $T$-cyclic $(\alpha, \beta)$ admissible mapping. Indeed, if $\alpha(T x)=e^{x} \geq 1$, then $x \geq 0$ which implies $f x \geq 0$ and so $\beta(f x)=e^{f x} \geq 1$. Also, if $\beta(T y)=e^{-y} \geq 1$, then $y \leq 0$, which implies $f y \leq 0$ and so $\alpha(f y)=$ $e^{-f y} \geq 1$.

Definition 5 Let $(X, d)$ be a metric space and let $f$ be a $T$-cyclic $(\alpha, \beta)$-admissible mapping. We say that $f$ is a $T$-cyclic $(\alpha, \beta)$-contractive mapping if

$$
\alpha(T x) \beta(T y) \geq 1 \quad \Rightarrow \quad \varphi(d(f x, f y)) \leq \eta(M(x, y)),
$$


for all $x, y \in X$, where

$$
M(x, y)=\psi\left(d(T x, T y), d(T x, f x), d(T y, f y), \frac{1}{2}[d(T x, f y)+d(T y, f x)]\right),
$$

$\psi \in \Psi, \varphi$ is an altering distance function and $\eta:[0, \infty) \rightarrow[0, \infty)$ is a nondecreasing function and continuous from the right with the condition $\varphi(t)>\eta(t)$ for all $t>0$.

Theorem 1 Let $(X, d)$ be a complete metric space and let $f$ and $T$ be self-mappings on $X$ such that $f X \subset T X$. Let $f$ be a T-cyclic $(\alpha, \beta)$-contractive mapping. Assume that TX is a closed subset of $X$ and the following conditions are satisfied:

(i) there exists $x_{0} \in X$ such that $\alpha\left(T x_{0}\right) \geq 1$ and $\beta\left(T x_{0}\right) \geq 1$;

(ii) if $\left\{x_{n}\right\}$ is a sequence in $X$ such that $x_{n} \rightarrow x$ and $\beta\left(x_{n}\right) \geq 1$ for all $n$, then $\beta(x) \geq 1$;

(iii) $\alpha(T u) \geq 1$ and $\beta(T v) \geq 1$ whenever $f u=T u$ and $f v=T v$.

Then $f$ and $T$ have a unique point of coincidence in $X$. Moreover, if $f$ and $T$ are weakly compatible, then $f$ and $T$ have a unique common fixed point.

Proof Let $x_{0} \in X$ such that $\alpha\left(T x_{0}\right) \geq 1$ and $\beta\left(T x_{0}\right) \geq 1$. Define the sequences $\left\{x_{n}\right\}$ and $\left\{y_{n}\right\}$ in $X$ by

$$
y_{n}=f x_{n}=T x_{n+1}, \quad n \in \mathbb{N} \cup\{0\} .
$$

If $y_{n}=y_{n+1}$, then $y_{n+1}$ is a point of coincidence of $f$ and $T$. Suppose that $y_{n} \neq y_{n+1}$ for all $n \in \mathbb{N}$. Since $f$ is a $T$-cyclic $(\alpha, \beta)$-admissible mapping and $\alpha\left(T x_{0}\right) \geq 1$ then $\beta\left(f x_{0}\right)=\beta\left(T x_{1}\right) \geq 1$, which implies $\alpha\left(T x_{2}\right)=\alpha\left(f x_{1}\right) \geq 1$. By continuing this process, we get $\alpha\left(T x_{2 n}\right) \geq 1$ and $\beta\left(T x_{2 n+1}\right) \geq 1$ for all $n \in \mathbb{N} \cup\{0\}$. Similarly, since $f$ is a $T$-cyclic $(\alpha, \beta)$-admissible mapping and $\beta\left(T x_{0}\right) \geq 1$, we have $\beta\left(T x_{2 n}\right) \geq 1$ and $\alpha\left(T x_{2 n+1}\right) \geq 1$ for all $n \in \mathbb{N} \cup\{0\}$, that is, $\alpha\left(T x_{n}\right) \geq 1$ and $\beta\left(T x_{n}\right) \geq 1$ for all $n \in \mathbb{N} \cup\{0\}$. Equivalently, $\alpha\left(T x_{n}\right) \beta\left(T x_{n+1}\right) \geq 1$ for all $n \in \mathbb{N} \cup\{0\}$. Therefore by (2.1) and using (2.2), we get

$$
\varphi\left(d\left(y_{n}, y_{n+1}\right)\right)=\varphi\left(d\left(f x_{n}, f x_{n+1}\right)\right) \leq \eta\left(M\left(x_{n}, x_{n+1}\right)\right)<\varphi\left(M\left(x_{n}, x_{n+1}\right)\right) .
$$

Since $\varphi$ is nondecreasing, we have

$$
d\left(y_{n}, y_{n+1}\right)<M\left(x_{n}, x_{n+1}\right),
$$

where

$$
\begin{aligned}
M & \left(x_{n}, x_{n+1}\right) \\
& =\psi\left(d\left(T x_{n}, T x_{n+1}\right), d\left(T x_{n}, f x_{n}\right), d\left(T x_{n+1}, f x_{n+1}\right), \frac{1}{2}\left[d\left(T x_{n}, f x_{n+1}\right)+d\left(T x_{n+1}, f x_{n}\right)\right]\right) \\
& =\psi\left(d\left(y_{n-1}, y_{n}\right), d\left(y_{n-1}, y_{n}\right), d\left(y_{n}, y_{n+1}\right), \frac{1}{2}\left[d\left(y_{n-1}, y_{n+1}\right)+d\left(y_{n}, y_{n}\right)\right]\right) \\
& \leq \psi\left(d\left(y_{n-1}, y_{n}\right), d\left(y_{n-1}, y_{n}\right), d\left(y_{n}, y_{n+1}\right), \frac{1}{2}\left[d\left(y_{n-1}, y_{n}\right)+d\left(y_{n}, y_{n+1}\right)\right]\right) .
\end{aligned}
$$


Thus, from (2.4), we obtain

$$
\begin{aligned}
d\left(y_{n}, y_{n+1}\right) & <M\left(x_{n}, x_{n+1}\right) \\
& \leq \psi\left(d\left(y_{n-1}, y_{n}\right), d\left(y_{n-1}, y_{n}\right), d\left(y_{n}, y_{n+1}\right), \frac{1}{2}\left[d\left(y_{n-1}, y_{n}\right)+d\left(y_{n}, y_{n+1}\right)\right]\right) .
\end{aligned}
$$

If $d\left(y_{n-1}, y_{n}\right) \leq d\left(y_{n}, y_{n+1}\right)$ for some $n \in \mathbb{N}$, then

$$
\begin{aligned}
d\left(y_{n}, y_{n+1}\right) & <\psi\left(d\left(y_{n-1}, y_{n}\right), d\left(y_{n-1}, y_{n}\right), d\left(y_{n}, y_{n+1}\right), \frac{1}{2}\left[d\left(y_{n-1}, y_{n}\right)+d\left(y_{n}, y_{n+1}\right)\right]\right) \\
& \leq \psi\left(d\left(y_{n}, y_{n+1}\right), d\left(y_{n}, y_{n+1}\right), d\left(y_{n}, y_{n+1}\right), d\left(y_{n}, y_{n+1}\right)\right) \\
& \leq d\left(y_{n}, y_{n+1}\right),
\end{aligned}
$$

which is a contradiction, and hence $d\left(y_{n}, y_{n+1}\right)<d\left(y_{n-1}, y_{n}\right)$ for all $n \in \mathbb{N}$. Therefore, the sequence $\left\{d\left(y_{n}, y_{n+1}\right)\right\}$ is decreasing and bounded below. Thus, there exists $r \geq 0$ such that $\lim _{n \rightarrow \infty} d\left(y_{n}, y_{n+1}\right)=r$. Assume $r>0$. Also, from (2.3), (2.5) and using the properties of $\psi$, we deduce

$$
\begin{aligned}
\varphi\left(d\left(y_{n}, y_{n+1}\right)\right) & \leq \eta\left(M\left(x_{n}, x_{n+1}\right)\right) \\
& \leq \eta\left(\psi\left(d\left(y_{n-1}, y_{n}\right), d\left(y_{n-1}, y_{n}\right), d\left(y_{n}, y_{n+1}\right), \frac{1}{2}\left[d\left(y_{n-1}, y_{n}\right)+d\left(y_{n}, y_{n+1}\right)\right]\right)\right) \\
& \leq \eta\left(\psi\left(d\left(y_{n-1}, y_{n}\right), d\left(y_{n-1}, y_{n}\right), d\left(y_{n-1}, y_{n}\right), d\left(y_{n-1}, y_{n}\right)\right)\right) \\
& \leq \eta\left(d\left(y_{n-1}, y_{n}\right)\right) .
\end{aligned}
$$

Considering the properties of $\varphi$ and $\eta$, letting $n \rightarrow \infty$ in (2.6), we get

$$
\begin{aligned}
\varphi(r) & =\lim _{n \rightarrow \infty} \varphi\left(d\left(y_{n}, y_{n+1}\right)\right) \\
& \leq \lim _{n \rightarrow \infty} \eta\left(d\left(y_{n-1}, y_{n}\right)\right)=\eta(r)<\varphi(r),
\end{aligned}
$$

which implies $r=0$ and so

$$
\lim _{n \rightarrow \infty} d\left(y_{n}, y_{n+1}\right)=0
$$

Now, we prove that $\left\{y_{n}\right\}$ is a Cauchy sequence. Suppose, to the contrary, that $\left\{y_{n}\right\}$ is not a Cauchy sequence. Then there exists an $\varepsilon>0$ for which we can find two subsequences $\left\{y_{m_{k}}\right\}$ and $\left\{y_{n_{k}}\right\}$ of $\left\{y_{n}\right\}$ such that $m_{k}$ is the smallest index for which $m_{k}>n_{k}>k$ and

$$
d\left(y_{m_{k}}, y_{n_{k}}\right) \geq \varepsilon \quad \text { and } \quad d\left(y_{m_{k}-1}, y_{n_{k}}\right)<\varepsilon
$$

Using the triangular inequality and (2.8), we have

$$
\begin{aligned}
\varepsilon & \leq d\left(y_{n_{k}}, y_{m_{k}}\right) \leq d\left(y_{n_{k}}, y_{m_{k}-1}\right)+d\left(y_{m_{k}-1}, y_{m_{k}}\right) \\
& <\varepsilon+d\left(y_{m_{k}-1}, y_{m_{k}}\right) .
\end{aligned}
$$


By taking $k \rightarrow \infty$ in the above inequality and using (2.7), we obtain

$$
\lim _{k \rightarrow \infty} d\left(y_{n_{k}}, y_{m_{k}}\right)=\varepsilon
$$

By using (2.7), (2.9), and the triangular inequality, we deduce

$$
\begin{aligned}
& \lim _{k \rightarrow \infty} d\left(y_{n_{k}-1}, y_{m_{k}}\right)=\varepsilon, \\
& \lim _{k \rightarrow \infty} d\left(y_{m_{k}-1}, y_{n_{k}}\right)=\varepsilon, \\
& \lim _{k \rightarrow \infty} d\left(y_{m_{k}-1}, y_{n_{k}-1}\right)=\varepsilon .
\end{aligned}
$$

From (2.1), we get

$$
\begin{aligned}
\varphi\left(d\left(y_{n_{k}}, y_{m_{k}}\right)\right) & =\varphi\left(d\left(f x_{n_{k}}, f x_{m_{k}}\right)\right) \\
& \leq \eta\left(M\left(x_{n_{k}}, x_{m_{k}}\right)\right),
\end{aligned}
$$

where

$$
\begin{aligned}
M\left(x_{n_{k}}, x_{m_{k}}\right)= & \psi\left(d\left(T x_{n_{k}}, T x_{m_{k}}\right), d\left(T x_{n_{k}}, f x_{n_{k}}\right), d\left(T x_{m_{k}}, f x_{m_{k}}\right),\right. \\
& \left.\frac{1}{2}\left[d\left(T x_{n_{k}}, f x_{m_{k}}\right)+d\left(T x_{m_{k}}, f x_{n_{k}}\right)\right]\right) \\
\leq & \psi\left(\max \left\{\varepsilon, d\left(y_{n_{k}-1}, y_{m_{k}-1}\right)\right\}, d\left(y_{n_{k}-1}, y_{n_{k}}\right), d\left(y_{m_{k}-1}, y_{m_{k}}\right),\right. \\
& \left.\max \left\{\varepsilon, \frac{1}{2}\left[d\left(y_{n_{k}-1}, y_{m_{k}}\right)+d\left(y_{m_{k}-1}, y_{n_{k}}\right)\right]\right\}\right) .
\end{aligned}
$$

Now, from the properties of $\varphi, \psi$, and $\eta$ and using (2.7), (2.9), (2.10), and the above inequality, as $k \rightarrow \infty$ in (2.11), we have

$$
\varphi(\varepsilon) \leq \eta(\psi(\varepsilon, 0,0, \varepsilon)) \leq \eta(\varepsilon)<\varphi(\varepsilon)
$$

which implies that $\varepsilon=0$, a contradiction with $\varepsilon>0$. Thus $\left\{y_{n}\right\}$ is a Cauchy sequence in $X$. From the completeness of $(X, d)$, there exists $z \in X$ such that

$$
\lim _{n \rightarrow \infty} y_{n}=z
$$

From (2.2) and (2.12), we obtain

$$
f x_{n} \rightarrow z \quad \text { and } \quad T x_{n+1} \rightarrow z
$$

Since $T X$ is closed, by (2.13), $z \in T X$. Therefore, there exists $u \in X$ such that $T u=z$. As $y_{n} \rightarrow z$ and $\beta\left(y_{n}\right)=\beta\left(T x_{n+1}\right) \geq 1$ for all $n \in \mathbb{N}$, by (ii), $\beta(z)=\beta(T u) \geq 1$. Thus, $\alpha\left(T x_{n}\right) \beta(T u) \geq 1$ for all $n \in \mathbb{N}$. 
Now, applying inequality (2.1), we get

$$
\varphi\left(d\left(f x_{n}, f u\right)\right) \leq \eta\left(M\left(x_{n}, u\right)\right)
$$

where

$$
\begin{aligned}
& M\left(x_{n}, u\right) \\
& \quad=\psi\left(d\left(T x_{n}, T u\right), d\left(T x_{n}, f x_{n}\right), d(T u, f u), \frac{1}{2}\left[d\left(T x_{n}, f u\right)+d\left(T u, f x_{n}\right)\right]\right) \\
& \quad \leq \psi\left(d\left(T x_{n}, T u\right), d\left(T x_{n}, f x_{n}\right), d(T u, f u), \frac{1}{2} \max \left\{d(T u, f u),\left[d\left(T x_{n}, f u\right)+d\left(T u, f x_{n}\right)\right]\right\}\right) .
\end{aligned}
$$

Taking $k \rightarrow \infty$ in the inequality (2.14) and using the properties of $\varphi, \psi, \eta$, and the above inequality we have

$$
\begin{aligned}
\varphi(d(z, f u)) & \leq \eta\left(\psi\left(0,0, d(z, f u), \frac{1}{2} d(z, f u)\right)\right) \\
& \leq \eta(d(z, f u))<\varphi(d(z, f u)),
\end{aligned}
$$

which implies $d(z, f u)=0$, that is, $z=f u$. Thus, we deduce

$$
z=f u=T u
$$

and so $z$ is a point of coincidence for $f$ and $T$. The uniqueness of the point of coincidence is a consequence of the conditions (2.1) and (iii), and so we omit the details.

By (2.15) and using the weak compatibility of $f$ and $T$, we obtain

$$
f z=f T u=T f u=T z
$$

and so $f z=T z$. Uniqueness of the point of coincidence implies $z=f z=T z$. Consequently, $z$ is a unique common fixed point of $f$ and $T$.

Example 2 Let $X=\mathbb{R}$ be endowed with the usual metric $d(x, y)=|x-y|$ for all $x, y \in X$. Also, let $\varphi(t)=t$ and $\eta(t)=\frac{2}{3} t$ for all $t \geq 0$, and $\psi\left(t_{1}, t_{2}, t_{3}, t_{4}\right)=\max \left\{t_{1}, t_{2}, t_{3}, t_{4}\right\}$ for all $t_{1}, t_{2}, t_{3}, t_{4} \geq 0$.

Now, define the self-mappings $f$ and $T$ on $X$ by

$$
f x=\left\{\begin{array}{ll}
-\frac{x}{3} & \text { if } x \in[0,1], \\
\frac{x}{9} & \text { if } x \in \mathbb{R} \backslash[0,1]
\end{array} \quad \text { and } \quad T x= \begin{cases}\frac{x}{3} & \text { if } x \in[-1,0] \\
\frac{x}{4} & \text { if } x \in \mathbb{R} \backslash[-1,0]\end{cases}\right.
$$

Then it is clear that $f X \subset T X$. Also, define the mappings $\alpha, \beta: X \rightarrow[0, \infty)$ by

$$
\alpha(x)= \begin{cases}e^{x} & \text { if } x \in\left(-\infty,-\frac{1}{3}\right) \\ e^{-x} & \text { if } x \in\left[-\frac{1}{3}, 0\right] \\ 0 & \text { if } x \in(0, \infty)\end{cases}
$$


Figure 1 Plot of $T x$ (in blue) and $f x$ (in red) on [-2, 2].

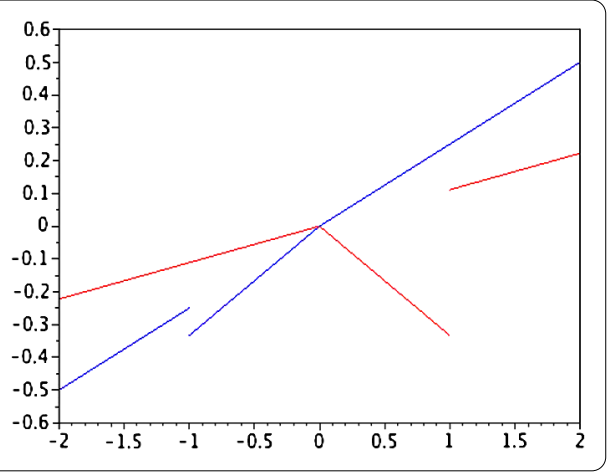

Figure 2 Zoom of the plot in Figure 1. In violet, we have $\left\{y_{n}\right\}=\left\{f x_{n}\right\}=\left\{T x_{n+1}\right\}$ at the starting point $x_{0}$ $=-1 / 9$.

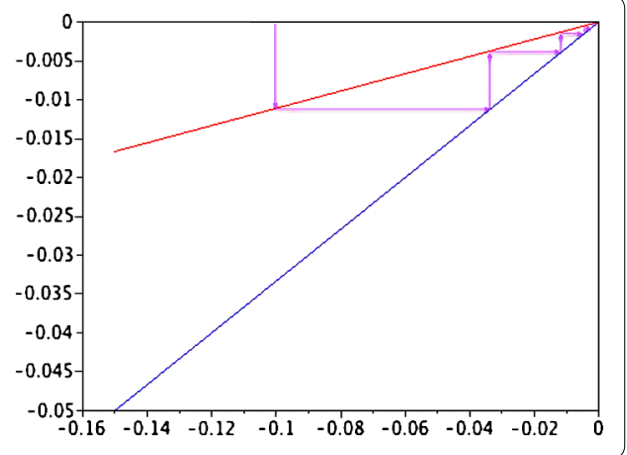

and

$$
\beta(x)= \begin{cases}e^{-x} & \text { if } x \in\left[-\frac{1}{9}, 0\right] \\ 0 & \text { if } x \in \mathbb{R} \backslash\left[-\frac{1}{9}, 0\right] .\end{cases}
$$

Let $x \in X$ such that $\alpha(T x) \geq 1$ so that $T x \in\left[-\frac{1}{3}, 0\right]$ and hence $x \in[-1,0]$. By the definitions of $f$ and $\beta$, we have $f x \in\left[-\frac{1}{9}, 0\right]$ and so $\beta(f x) \geq 1$.

Similarly, one can show that if $\beta(T x) \geq 1$ then $\alpha(f x) \geq 1$. Thus, $f$ is a $T$-cyclic $(\alpha, \beta)$ admissible mapping. Moreover, the conditions $\alpha\left(T x_{0}\right) \geq 1$ and $\beta\left(T x_{0}\right) \geq 1$ are satisfied with $x_{0}=-\frac{1}{9}$.

Now, let $\left\{x_{n}\right\}$ be a sequence in $X$ such that $\beta\left(x_{n}\right) \geq 1$ for all $n \in \mathbb{N}$ and $x_{n} \rightarrow x$ as $n \rightarrow \infty$. Then, by the definition of $\beta$, we have $x_{n} \in\left[-\frac{1}{9}, 0\right]$ for all $n \in \mathbb{N}$ and so $x \in\left[-\frac{1}{9}, 0\right]$, that is, $\beta(x) \geq 1$.

Next, we prove that $f$ is a $T$-cyclic $(\alpha, \beta)$-contractive mapping. Let $\alpha(T x) \beta(T y) \geq 1$, then $T x \in\left[-\frac{1}{3}, 0\right], T y \in\left[-\frac{1}{9}, 0\right]$ and so $x \in[-1,0], y \in\left[-\frac{1}{3}, 0\right]$. Thus, we get

$$
\begin{aligned}
\varphi(d(f x, f y)) & =|f x-f y|=\frac{1}{9}|x-y| \\
& \leq \frac{2}{9}|x-y|=\frac{2}{3}|T x-T y| \\
& \leq \frac{2}{3} M(x, y)=\eta(M(x, y)) .
\end{aligned}
$$


Obviously, assumption (iii) of Theorem 1 is satisfied. Consequently, all conditions of Theorem 1 hold, and hence $f$ and $T$ have a unique common fixed point. Here 0 is the common fixed point of $f$ and $T$; see Figures 1 and 2 .

Corollary 1 Let $(X, d)$ be a complete metric space and let $f$ and $T$ be self-mappings on $X$ such that $f X \subset T X$. Let $f$ be a $T$-cyclic $(\alpha, \beta)$-admissible mapping such that

$$
\alpha(T x) \beta(T y) \varphi(d(f x, f y)) \leq \eta(M(x, y))
$$

for all $x, y \in X$, where $\varphi$ is an altering distance function and $\eta:[0, \infty) \rightarrow[0, \infty)$ is a nondecreasing function and continuous from the right with the condition $\varphi(t)>\eta(t)$ for all $t>0$ and

$$
M(x, y)=\max \left\{d(T x, T y), d(T x, f x), d(T y, f y), \frac{1}{2}[d(T x, f y)+d(T y, f x)]\right\} .
$$

Assume that $T X$ is a closed subset of $X$ and the following conditions are satisfied:

(i) there exists $x_{0} \in X$ such that $\alpha\left(T x_{0}\right) \geq 1$ and $\beta\left(T x_{0}\right) \geq 1$;

(ii) if $\left\{x_{n}\right\}$ is a sequence in $X$ such that $x_{n} \rightarrow x$ and $\beta\left(x_{n}\right) \geq 1$ for all $n$, then $\beta(x) \geq 1$;

(iii) $\alpha(T u) \geq 1$ and $\beta(T v) \geq 1$ whenever $f u=T u$ and $f v=T v$.

Then $f$ and $T$ have a unique point of coincidence in $X$. Moreover, if $f$ and $T$ are weakly compatible, then $f$ and $T$ have a unique common fixed point.

Proof Let $\alpha(T x) \beta(T y) \geq 1$ for $x, y \in X$. If we take $\psi\left(t_{1}, t_{2}, t_{3}, t_{4}\right)=\max \left\{t_{1}, t_{2}, t_{3}, t_{4}\right\}$ in Theorem 1 , then from (2.17), we have

$$
\varphi(d(f x, f y)) \leq \eta(M(x, y)) .
$$

This implies that the inequality (2.1) holds. Therefore, the proof follows from Theorem 1.

If we choose $T=I_{X}$ in Theorem 1, we have the following corollary.

Corollary 2 Let $(X, d)$ be a complete metric space and $f: X \rightarrow X$ be a cyclic $(\alpha, \beta)$ admissible mapping such that

$$
\alpha(x) \beta(y) \geq 1 \quad \Rightarrow \quad \varphi(d(f x, f y)) \leq \eta\left(M_{f}(x, y)\right),
$$

for all $x, y \in X$, where $\psi \in \Psi, \varphi$ is an altering distance function and $\eta:[0, \infty) \rightarrow[0, \infty)$ is a nondecreasing function and continuous from the right with the condition $\varphi(t)>\eta(t)$ for all $t>0$ and

$$
M_{f}(x, y)=\psi\left(d(x, y), d(x, f x), d(y, f y), \frac{1}{2}[d(x, f y)+d(y, f x)]\right) .
$$

Assume that the following conditions are satisfied:

(i) there exists $x_{0} \in X$ such that $\alpha\left(x_{0}\right) \geq 1$ and $\beta\left(x_{0}\right) \geq 1$;

(ii) if $\left\{x_{n}\right\}$ is a sequence in $X$ such that $x_{n} \rightarrow x$ and $\beta\left(x_{n}\right) \geq 1$ for all $n$, then $\beta(x) \geq 1$; 
(iii) $\alpha(u) \geq 1$ and $\beta(v) \geq 1$ whenever $f u=u$ and $f v=v$.

Then $f$ has a unique fixed point.

If we take $\eta(t)=\varphi(t)-\eta^{1}(t)$ in Corollary 2, we have the following corollary.

Corollary 3 Let $(X, d)$ be a complete metric space and $f: X \rightarrow X$ be a cyclic $(\alpha, \beta)$ admissible mapping such that

$$
\alpha(x) \beta(y) \geq 1 \quad \Rightarrow \quad \varphi(d(f x, f y)) \leq \varphi\left(M_{f}(x, y)\right)-\eta^{1}\left(M_{f}(x, y)\right)
$$

for all $x, y \in X$, where $\psi \in \Psi, \varphi$ is an altering distance function and $\eta^{1}:[0, \infty) \rightarrow[0, \infty)$ is such that $\varphi(t)-\eta^{1}(t)$ is nondecreasing and $\eta^{1}(t)$ is continuous from the right, with the condition $\varphi(t)>\eta^{1}(t)$ for all $t>0$.

Assume that the following conditions are satisfied:

(i) there exists $x_{0} \in X$ such that $\alpha\left(x_{0}\right) \geq 1$ and $\beta\left(x_{0}\right) \geq 1$;

(ii) if $\left\{x_{n}\right\}$ is a sequence in $X$ such that $x_{n} \rightarrow x$ and $\beta\left(x_{n}\right) \geq 1$ for all $n$, then $\beta(x) \geq 1$;

(iii) $\alpha(u) \geq 1$ and $\beta(v) \geq 1$ whenever $f u=u$ and $f v=v$.

Then $f$ has a unique fixed point.

If we take $\varphi(t)=t$ in Corollary 3 , we have the following corollary.

Corollary 4 Let $(X, d)$ be a complete metric space and $f: X \rightarrow X$ be a cyclic $(\alpha, \beta)$ admissible mapping such that

$$
\alpha(x) \beta(y) \geq 1 \quad \Rightarrow \quad d(f x, f y) \leq M_{f}(x, y)-\eta^{1}\left(M_{f}(x, y)\right),
$$

for all $x, y \in X$, where $\psi \in \Psi$ and $\eta^{1}:[0, \infty) \rightarrow[0, \infty)$ is such that $t-\eta^{1}(t)$ is nondecreasing and $\eta^{1}(t)$ is continuous from the right, with the condition $\eta^{1}(t)>0$ for all $t>0$.

Assume that the following conditions are satisfied:

(i) there exists $x_{0} \in X$ such that $\alpha\left(x_{0}\right) \geq 1$ and $\beta\left(x_{0}\right) \geq 1$;

(ii) if $\left\{x_{n}\right\}$ is a sequence in $X$ such that $x_{n} \rightarrow x$ and $\beta\left(x_{n}\right) \geq 1$ for all $n$, then $\beta(x) \geq 1$;

(iii) $\alpha(u) \geq 1$ and $\beta(v) \geq 1$ whenever $f u=u$ and $f v=v$.

Then $f$ has a unique fixed point.

We denote by $\Phi$ the family of all functions $\phi: \mathbb{R}_{+}^{4} \rightarrow \mathbb{R}_{+}$such that

$\left(\phi_{1}\right) \phi$ is nondecreasing in each coordinate and continuous;

$\left(\phi_{2}\right) \phi(t, t, t, t) \leq t, \phi\left(t, \frac{t}{2}, t, 0\right) \leq t$ and $\phi\left(0, \frac{t}{2}, 0, t\right) \leq t$ for all $t>0$;

$\left(\phi_{3}\right) \phi\left(t_{1}, t_{2}, t_{3}, t_{4}\right)=0$ if and only if $t_{1}=t_{2}=t_{3}=t_{4}=0$.

Definition 6 Let $(X, d)$ be a metric space and let $f$ be a $T$-cyclic $(\alpha, \beta)$-admissible mapping. We say that $f$ is a $T$-cyclic $(\alpha, \beta)$-rational contractive mapping if

$$
\alpha(T x) \beta(T y) \geq 1 \Rightarrow \varphi(d(f x, f y)) \leq \eta(N(x, y)),
$$

for all $x, y \in X$, where

$$
N(x, y)=\phi\left(d(T x, T y), \frac{1}{2} d(T x, f y), d(T y, f x), \frac{[1+d(T x, f x)] d(T y, f y)}{1+d(T x, T y)}\right),
$$


$\phi \in \Phi, \varphi$ is an altering distance function and $\eta:[0, \infty) \rightarrow[0, \infty)$ is a nondecreasing function and continuous from the right with the condition $\varphi(t)>\eta(t)$ for all $t>0$.

Theorem 2 Let $(X, d)$ be a complete metric space and let $f$ and $T$ be self-mappings on $X$ such that $f X \subset T X$. Let $f$ be a T-cyclic $(\alpha, \beta)$-rational contractive mapping. Assume that $T X$ is a closed subset of $X$ and the following conditions are satisfied:

(i) there exists $x_{0} \in X$ such that $\alpha\left(T x_{0}\right) \geq 1$ and $\beta\left(T x_{0}\right) \geq 1$;

(ii) if $\left\{x_{n}\right\}$ is a sequence in $X$ such that $x_{n} \rightarrow x$ and $\beta\left(x_{n}\right) \geq 1$ for all $n$, then $\beta(x) \geq 1$;

(iii) $\alpha(T u) \geq 1$ and $\beta(T v) \geq 1$ whenever $f u=T u$ and $f v=T v$.

Then $f$ and $T$ have a unique point of coincidence in $X$. Moreover, iff and $T$ are weakly compatible, then $f$ and $T$ have a unique common fixed point.

Proof Similar to the proof of Theorem 1, we define sequences $\left\{x_{n}\right\}$ and $\left\{y_{n}\right\}$ in $X$ by $y_{n}=$ $f x_{n}=T x_{n+1}$ and note that $\alpha\left(T x_{n}\right) \beta\left(T x_{n+1}\right) \geq 1$ for all $n \in \mathbb{N} \cup\{0\}$. Also we assume that $y_{n} \neq$ $y_{n-1}$ for all $n \in \mathbb{N}$. Then by (2.21), we have

$$
\varphi\left(d\left(y_{n}, y_{n+1}\right)\right)=\varphi\left(d\left(f x_{n}, f x_{n+1}\right)\right) \leq \eta\left(N\left(x_{n}, x_{n+1}\right)\right)<\varphi\left(N\left(x_{n}, x_{n+1}\right)\right) .
$$

Since $\varphi$ is nondecreasing, we get

$$
d\left(y_{n}, y_{n+1}\right)<N\left(x_{n}, x_{n+1}\right),
$$

where

$$
\begin{aligned}
N\left(x_{n}, x_{n+1}\right)= & \phi\left(d\left(T x_{n}, T x_{n+1}\right), \frac{1}{2} d\left(T x_{n}, f x_{n+1}\right), d\left(T x_{n+1}, f x_{n}\right),\right. \\
& \left.\frac{\left[1+d\left(T x_{n}, f x_{n}\right)\right] d\left(T x_{n+1}, f x_{n+1}\right)}{1+d\left(T x_{n}, T x_{n+1}\right)}\right) \\
= & \phi\left(d\left(y_{n-1}, y_{n}\right), \frac{1}{2} d\left(y_{n-1}, y_{n+1}\right), d\left(y_{n}, y_{n}\right), \frac{\left[1+d\left(y_{n-1}, y_{n}\right)\right] d\left(y_{n}, y_{n+1}\right)}{1+d\left(y_{n-1}, y_{n}\right)}\right) \\
\leq & \phi\left(d\left(y_{n-1}, y_{n}\right), \frac{1}{2}\left[d\left(y_{n-1}, y_{n}\right)+d\left(y_{n}, y_{n+1}\right)\right], 0, d\left(y_{n}, y_{n+1}\right)\right) .
\end{aligned}
$$

Thus, from (2.23), we deduce

$$
\begin{aligned}
d\left(y_{n}, y_{n+1}\right) & <N\left(x_{n}, x_{n+1}\right) \\
& \leq \phi\left(d\left(y_{n-1}, y_{n}\right), \frac{1}{2}\left[d\left(y_{n-1}, y_{n}\right)+d\left(y_{n}, y_{n+1}\right)\right], 0, d\left(y_{n}, y_{n+1}\right)\right) .
\end{aligned}
$$

If $d\left(y_{n-1}, y_{n}\right) \leq d\left(y_{n}, y_{n+1}\right)$ for some $n \in \mathbb{N}$, then

$$
\begin{aligned}
d\left(y_{n}, y_{n+1}\right) & <\phi\left(d\left(y_{n-1}, y_{n}\right), \frac{1}{2}\left[d\left(y_{n-1}, y_{n}\right)+d\left(y_{n}, y_{n+1}\right)\right], 0, d\left(y_{n}, y_{n+1}\right)\right) \\
& \leq \phi\left(d\left(y_{n}, y_{n+1}\right), d\left(y_{n}, y_{n+1}\right), d\left(y_{n}, y_{n+1}\right), d\left(y_{n}, y_{n+1}\right)\right) \\
& \leq d\left(y_{n}, y_{n+1}\right),
\end{aligned}
$$


which is a contradiction, and hence $d\left(y_{n}, y_{n+1}\right)<d\left(y_{n-1}, y_{n}\right)$ for all $n \in \mathbb{N}$. Therefore, the sequence $\left\{d\left(y_{n}, y_{n+1}\right)\right\}$ is decreasing and bounded from below. Thus, there exists $\delta \geq 0$ such that $\lim _{n \rightarrow \infty} d\left(y_{n}, y_{n+1}\right)=\delta$. Also, from (2.22), (2.24) and using the properties of $\varphi$ and $\eta$, we obtain

$$
\begin{aligned}
& \varphi\left(d\left(y_{n}, y_{n+1}\right)\right) \\
& \quad \leq \eta\left(N\left(x_{n}, x_{n+1}\right)\right) \\
& \quad \leq \eta\left(\phi\left(d\left(y_{n-1}, y_{n}\right), \frac{1}{2}\left[d\left(y_{n-1}, y_{n}\right)+d\left(y_{n}, y_{n+1}\right)\right], 0, d\left(y_{n}, y_{n+1}\right)\right)\right) \\
& \quad \leq \eta\left(\phi\left(d\left(y_{n-1}, y_{n}\right), d\left(y_{n-1}, y_{n}\right), d\left(y_{n-1}, y_{n}\right), d\left(y_{n-1}, y_{n}\right)\right)\right) \\
& \quad \leq \eta\left(d\left(y_{n-1}, y_{n}\right)\right)<\varphi\left(d\left(y_{n-1}, y_{n}\right)\right) .
\end{aligned}
$$

Consider the properties of $\varphi$ and $\eta$, letting $n \rightarrow \infty$ in (2.25), we get

$$
\begin{aligned}
\varphi(\delta) & =\lim _{n \rightarrow \infty} \varphi\left(d\left(y_{n}, y_{n+1}\right)\right) \\
& \leq \lim _{n \rightarrow \infty} \eta\left(d\left(y_{n-1}, y_{n}\right)\right)=\eta(\delta)<\varphi(\delta),
\end{aligned}
$$

which implies $\delta=0$ and so

$$
\lim _{n \rightarrow \infty} d\left(y_{n}, y_{n+1}\right)=0
$$

Now, we want to show that $\left\{y_{n}\right\}$ is a Cauchy sequence. Suppose, to the contrary, that $\left\{y_{n}\right\}$ is not a Cauchy sequence. Then there exists an $\varepsilon>0$ for which we can find two subsequences $\left\{y_{n_{k}}\right\}$ and $\left\{y_{m_{k}}\right\}$ of $\left\{y_{n}\right\}$ such that $n_{k}$ is the smallest index for which $n_{k}>m_{k}>k$ and

$$
d\left(y_{n_{k}}, y_{m_{k}}\right) \geq \varepsilon \quad \text { and } \quad d\left(y_{n_{k}-1}, y_{m_{k}}\right)<\varepsilon
$$

Using the triangular inequality and (2.27), we have

$$
\begin{aligned}
\varepsilon & \leq d\left(y_{m_{k}}, y_{n_{k}}\right) \leq d\left(y_{m_{k}}, y_{n_{k}-1}\right)+d\left(y_{n_{k}-1}, y_{n_{k}}\right) \\
& <\varepsilon+d\left(y_{n_{k}-1}, y_{n_{k}}\right) .
\end{aligned}
$$

By taking $k \rightarrow \infty$ in the above inequality and using (2.26), we obtain

$$
\lim _{k \rightarrow \infty} d\left(y_{m_{k}}, y_{n_{k}}\right)=\varepsilon
$$

By using (2.26), (2.28), and the triangular inequality, we deduce

$$
\begin{aligned}
& \lim _{k \rightarrow \infty} d\left(y_{n_{k}-1}, y_{m_{k}}\right)=\varepsilon, \\
& \lim _{k \rightarrow \infty} d\left(y_{m_{k}-1}, y_{n_{k}}\right)=\varepsilon, \\
& \lim _{k \rightarrow \infty} d\left(y_{m_{k}-1}, y_{n_{k}-1}\right)=\varepsilon .
\end{aligned}
$$


From (2.21), we get

$$
\varphi\left(d\left(y_{n_{k}}, y_{m_{k}}\right)\right)=\varphi\left(d\left(f x_{n_{k}}, f x_{m_{k}}\right)\right) \leq \eta\left(N\left(x_{n_{k}}, x_{m_{k}}\right)\right),
$$

where

$$
\begin{aligned}
N\left(x_{n_{k}}, x_{m_{k}}\right)= & \phi\left(d\left(T x_{n_{k}}, T x_{m_{k}}\right), \frac{1}{2} d\left(T x_{n_{k}}, f x_{m_{k}}\right), d\left(T x_{m_{k}}, f x_{n_{k}}\right),\right. \\
& \left.\frac{\left[1+d\left(T x_{n_{k}}, f x_{n_{k}}\right)\right] d\left(T x_{m_{k}}, f x_{m_{k}}\right)}{1+d\left(T x_{n_{k}}, T x_{m_{k}}\right)}\right) \\
= & \phi\left(d\left(y_{n_{k}-1}, y_{m_{k}-1}\right), \frac{1}{2} d\left(y_{n_{k}-1}, y_{m_{k}}\right), d\left(y_{m_{k}-1}, y_{n_{k}}\right),\right. \\
& \left.\frac{\left[1+d\left(y_{n_{k}-1}, y_{n_{k}}\right)\right] d\left(y_{m_{k}-1}, y_{m_{k}}\right)}{1+d\left(y_{n_{k}-1}, y_{m_{k}-1}\right)}\right) \\
\leq & \max \left\{\varepsilon, N\left(x_{n_{k}}, x_{m_{k}}\right)\right\} \\
= & \phi\left(\max \left\{\varepsilon, d\left(y_{n_{k}-1}, y_{m_{k}-1}\right)\right\}, \frac{1}{2} \max \left\{\varepsilon, d\left(y_{n_{k}-1}, y_{m_{k}}\right)\right\},\right. \\
& \left.\max \left\{\varepsilon, d\left(y_{m_{k}-1}, y_{n_{k}}\right)\right\}, \frac{\left[1+d\left(y_{n_{k}-1}, y_{n_{k}}\right)\right] d\left(y_{m_{k}-1}, y_{m_{k}}\right)}{1+d\left(y_{n_{k}-1}, y_{m_{k}-1}\right)}\right) .
\end{aligned}
$$

Therefore $\lim _{k \rightarrow \infty} \max \left\{\varepsilon, N\left(x_{n_{k}}, x_{m_{k}}\right)\right\}=\phi\left(\varepsilon, \frac{\varepsilon}{2}, \varepsilon, 0\right) \leq \varepsilon$.

Now, from the properties of $\varphi$ and $\eta$ and using (2.26), (2.28), (2.29), and the previous inequality, as $k \rightarrow \infty$ in (2.30), we have

$$
\varphi(\varepsilon)=\lim _{n \rightarrow \infty} \varphi\left(d\left(y_{n}, y_{n+1}\right)\right) \leq \lim _{n \rightarrow \infty} \eta\left(\max \left\{\varepsilon, N\left(x_{n_{k}}, x_{m_{k}}\right)\right\}\right) \leq \eta(\varepsilon)<\varphi(\varepsilon),
$$

which implies that $\varepsilon=0$, a contradiction with $\varepsilon>0$. Thus $\left\{y_{n}\right\}$ is a Cauchy sequence in $X$. From the completeness of $(X, d)$, there exists $w \in X$ such that

$$
\lim _{n \rightarrow \infty} y_{n}=w
$$

and so by (2.31), we obtain

$$
f x_{n} \rightarrow w \quad \text { and } \quad T x_{n+1} \rightarrow w
$$

Since $T X$ is closed, by (2.32), $w \in T X$. Therefore, there exists $v \in X$ such that $T v=w$. As $y_{n} \rightarrow w$ and $\beta\left(y_{n}\right)=\beta\left(T x_{n+1}\right) \geq 1$ for all $n \in \mathbb{N}$, by (ii), $\beta(w)=\beta(T v) \geq 1$. Thus, $\alpha\left(T x_{n}\right) \beta(T v) \geq 1$ for all $n \in \mathbb{N}$.

Now, applying inequality (2.21), we get

$$
\varphi\left(d\left(f x_{n}, f v\right)\right) \leq \eta\left(N\left(x_{n}, v\right)\right),
$$

where

$$
\begin{aligned}
N\left(x_{n}, v\right) \leq & \phi\left(d\left(T x_{n}, T v\right), \frac{1}{2} \max \left\{d(v, f v), d\left(T x_{n}, f v\right)\right\}, d\left(T v, f x_{n}\right),\right. \\
& \left.d(T v, f v) \max \left\{\frac{\left[1+d\left(T x_{n}, f x_{n}\right)\right]}{1+d\left(T x_{n}, T v\right)}, 1\right\}\right) .
\end{aligned}
$$


Taking $k \rightarrow \infty$ in the inequality (2.33), using the properties of $\varphi, \eta$ and the previous inequality we have

$$
\begin{aligned}
\varphi(d(w, f v)) & \leq \eta\left(\phi\left(0, \frac{1}{2} d(w, f v), 0, d(w, f v)\right)\right) \\
& \leq \eta(d(w, f v))<\varphi(d(w, f v)),
\end{aligned}
$$

which implies $d(w, f v)=0$, that is, $w=f v$. Thus, we deduce

$$
w=f v=T v,
$$

and so $w$ is a point of coincidence for $f$ and $T$. The uniqueness of the point of coincidence is a consequence of the conditions (2.21) and (iii), and so we omit the details.

By (2.34) and using the weak compatibility of $f$ and $T$, we obtain

$$
f w=f T v=T f v=T w .
$$

The uniqueness of the point of coincidence implies $w=f w=T w$. Consequently, $w$ is the unique common fixed point of $f$ and $T$.

Corollary 5 Let $(X, d)$ be a complete metric space and let $f$ and $T$ be self-mappings on $X$ such that $f X \subset T X$. Let $f$ be a $T$-cyclic $(\alpha, \beta)$-admissible mapping such that

$$
\alpha(T x) \beta(T y) \varphi(d(f x, f y)) \leq \eta(N(x, y)),
$$

for all $x, y \in X$, where $\varphi$ is an altering distance function and $\eta:[0, \infty) \rightarrow[0, \infty)$ is a nondecreasing function and continuous from the right with the condition $\varphi(t)>\eta(t)$ for all $t>0$ and

$$
N(x, y)=\max \left\{d(T x, T y), \frac{1}{2} d(T x, f y), d(T y, f x), \frac{[1+d(T x, f x)] d(T y, f y)}{1+d(T x, T y)}\right\} .
$$

Assume that $T X$ is a closed subset of $X$ and that the following conditions are satisfied:

(i) there exists $x_{0} \in X$ such that $\alpha\left(T x_{0}\right) \geq 1$ and $\beta\left(T x_{0}\right) \geq 1$;

(ii) if $\left\{x_{n}\right\}$ is a sequence in $X$ such that $x_{n} \rightarrow x$ and $\beta\left(x_{n}\right) \geq 1$ for all $n$, then $\beta(x) \geq 1$;

(iii) $\alpha(T u) \geq 1$ and $\beta(T v) \geq 1$ whenever $f u=T u$ and $f v=T v$.

Then $f$ and $T$ have a unique point of coincidence in X. Moreover, iff and $T$ are weakly compatible, then $f$ and $T$ have a unique common fixed point.

If we take $T=I_{X}$ and $\eta(t)=\varphi(t)-\eta^{1}(t)$ in Theorem 2, we have the following corollary.

Corollary 6 Let $(X, d)$ be a complete metric space and $f: X \rightarrow X$ be a cyclic $(\alpha, \beta)$ admissible mapping such that

$$
\alpha(x) \beta(y) \geq 1 \quad \Rightarrow \quad \varphi(d(f x, f y)) \leq \varphi\left(N_{f}(x, y)\right)-\eta^{1}\left(N_{f}(x, y)\right),
$$

for all $x, y \in X$, where $\phi \in \Phi, \varphi$ is an altering distance function and $\eta^{1}:[0, \infty) \rightarrow[0, \infty)$ is such that $\varphi(t)-\eta^{1}(t)$ is nondecreasing and $\eta^{1}(t)$ is continuous from the right, with the 
condition $\varphi(t)>\eta^{1}(t)$ for all $t>0$, and

$$
N_{f}(x, y)=\phi\left(d(x, y), \frac{1}{2} d(x, f y), d(y, f x), \frac{[1+d(x, f x)] d(y, f y)}{1+d(x, y)}\right) .
$$

Assume that the following conditions are satisfied:

(i) there exists $x_{0} \in X$ such that $\alpha\left(x_{0}\right) \geq 1$ and $\beta\left(x_{0}\right) \geq 1$;

(ii) if $\left\{x_{n}\right\}$ is a sequence in $X$ such that $x_{n} \rightarrow x$ and $\beta\left(x_{n}\right) \geq 1$ for all $n$, then $\beta(x) \geq 1$;

(iii) $\alpha(u) \geq 1$ and $\beta(v) \geq 1$ whenever $f u=u$ and $f v=v$.

Then $f$ has a unique fixed point.

If we take $\varphi(t)=t$ in Corollary 6 , we have the following corollary.

Corollary 7 Let $(X, d)$ be a complete metric space and $f: X \rightarrow X$ be a cyclic $(\alpha, \beta)$ admissible mapping such that

$$
\alpha(x) \beta(y) \geq 1 \quad \Rightarrow \quad d(f x, f y) \leq N_{f}(x, y)-\eta^{1}\left(N_{f}(x, y)\right)
$$

for all $x, y \in X$, where $\eta^{1}:[0, \infty) \rightarrow[0, \infty)$ is such that $t-\eta^{1}(t)$ is nondecreasing and $\eta^{1}(t)$ is continuous from the right, with the condition $\eta^{1}(t)>0$ for all $t>0$.

Assume that the following conditions are satisfied:

(i) there exists $x_{0} \in X$ such that $\alpha\left(x_{0}\right) \geq 1$ and $\beta\left(x_{0}\right) \geq 1$;

(ii) if $\left\{x_{n}\right\}$ is a sequence in $X$ such that $x_{n} \rightarrow x$ and $\beta\left(x_{n}\right) \geq 1$ for all $n$, then $\beta(x) \geq 1$;

(iii) $\alpha(u) \geq 1$ and $\beta(v) \geq 1$ whenever $f u=u$ and $f v=v$.

Then $f$ has a unique fixed point.

\section{Cyclic results}

The mappings $f, T: A \cup B \rightarrow A \cup B$ are called cyclic if $f A \subseteq T B$ and $f B \subseteq T A$, where $A, B$ are nonempty subsets of a metric space $(X, d)$. Moreover, $f$ and $T$ are called cyclic contraction if there exists $k \in(0,1)$ such that $d(f x, f y) \leq k d(T x, T y)$ for all $x \in A$ and $y \in B$. For more results see [16-19].

In this section we give some fixed point results involving cyclic mappings which can be regarded as consequences of the theorems presented in the previous section.

Theorem 3 Let $A$ and $B$ be two closed subsets of complete metric space $(X, d)$ such that $A \cap B \neq \emptyset$ and $f, T: A \cup B \rightarrow A \cup B$ be mappings such that $f A \subseteq T B$ and $f B \subseteq T A$. Assume that $T(A \cup B)$ is a closed subset of $X$ such that

$$
\varphi(d(f x, f y)) \leq \eta(M(x, y))
$$

for all $x \in A$ and $y \in B$, where $\varphi$ is an altering distance function and $\eta:[0, \infty) \rightarrow[0, \infty)$ is a nondecreasing function and continuous from the right with the condition $\varphi(t)>\eta(t)$ for all $t>0$.

(i) If $T$ is one to one then there exists $z \in A \cap B$ such that $f z=T z$.

(ii) Iff and $T$ are weakly compatible, then $f$ and $T$ have a unique common fixed point $z \in A \cap B$. 
Proof Define $\alpha, \beta: X \rightarrow[0, \infty)$ by

$$
\alpha(x)=\left\{\begin{array}{ll}
1, & \text { if } x \in T A, \\
0, & \text { otherwise }
\end{array} \text { and } \quad \beta(x)= \begin{cases}1, & \text { if } x \in T B \\
0, & \text { otherwise }\end{cases}\right.
$$

Let $\alpha(T x) \beta(T y) \geq 1$. Then $T x \in T A$ and $T y \in T B$. Since $T$ is one to one, we have $x \in A$ and $y \in B$. Hence, from (3.1) we obtain

$$
\varphi(d(f x, f y)) \leq \eta(M(x, y)) .
$$

Let $\alpha(T x) \geq 1$ for some $x \in X$, so $T x \in T A$ and then $x \in A$. Hence, $f x \in T B$ and so $\beta(f x) \geq 1$. Again, let $\beta(T x) \geq 1$ for some $x \in X$. Then $T x \in T B$ and so $x \in B$. Hence, $f x \in T A$ and then $\alpha(f x) \geq 1$. Therefore, $f$ is a $T$-cyclic $(\alpha, \beta)$-admissible mapping.

There exists an $x_{0} \in A \cap B$, as $A \cap B$ is nonempty. This implies that $T x_{0} \in T A$ and $T x_{0} \in$ $T B$ and so $\alpha\left(T x_{0}\right) \geq 1$ and $\beta\left(T x_{0}\right) \geq 1$.

Let $\left\{x_{n}\right\}$ be a sequence in $X$ such that $\beta\left(x_{n}\right) \geq 1$ for all $n \in \mathbb{N}$ and $x_{n} \rightarrow x$ as $n \rightarrow \infty$. Then $x_{n} \in T B$ for all $n \in \mathbb{N}$ and so $x \in T B$. This implies that $\beta(x) \geq 1$.

Then the conditions (i) and (ii) of Theorem 1 hold. So there exist $u, z \in A \cup B$ such that $u=f z=T z$. On the other hand, since $T$ is one to one, there exist $z_{1} \in A, z_{2} \in B$ such that $T z_{1}=T z_{2}=u$ implies $z_{1}=z_{2}=z$. Therefore, $u=T z$ for $z \in A \cap B$. If $f$ and $T$ are weakly compatible, following the proof of Theorem 1 , we have $u=f u=T u$. The uniqueness of the common fixed point follows from (3.1).

Similarly, we can prove the following theorem.

Theorem 4 Let $A$ and $B$ be two closed subsets of complete metric space $(X, d)$ such that $A \cap B \neq \emptyset$ and $f, T: A \cup B \rightarrow A \cup B$ be mappings such that $f A \subseteq T B$ and $f B \subseteq T A$. Assume that $T(A \cup B)$ is a closed subset of $X$ such that

$$
\varphi(d(f x, f y)) \leq \eta(N(x, y))
$$

for all $x \in A$ and $y \in B$, where $\varphi$ is an altering distance function and $\eta:[0, \infty) \rightarrow[0, \infty)$ is a nondecreasing function and continuous from the right with the condition $\varphi(t)>\eta(t)$ for all $t>0$.

(i) If $T$ is one to one then there exists $z \in A \cap B$ such that $f z=T z$.

(ii) Iff and $T$ are weakly compatible, then $f$ and $T$ have a unique common fixed point $z \in A \cap B$.

\section{Application to functional equations}

The existence and uniqueness of solutions of functional equations and system of functional equations arising in dynamic programming have been studied by using different fixed point theorems (see [20-22]).

Throughout this section, we assume that $U$ and $V$ are Banach spaces, $W \subseteq U$ is a state space, $D \subseteq V$ is a decision space. Now, we apply our results in order to prove the existence and uniqueness of the common solution of the following functional equations:

$$
P=\sup _{y \in D}\{p(x, y)+G(x, y, P(\tau(x, y)))\}, \quad x \in W,
$$


and

$$
Q=\sup _{y \in D}\{q(x, y)+K(x, y, Q(\tau(x, y)))\}, \quad x \in W,
$$

where $\tau: W \times D \rightarrow W, p, q: W \times D \rightarrow \mathbb{R}$ and $G, K: W \times D \times \mathbb{R} \rightarrow \mathbb{R}$. It is well known that equations of the type (4.1) and (4.2) provide useful tools for mathematical optimization, computer programming, and in dynamic programming (see [23, 24]).

Let $B(W)$ denote the space of all bounded real-valued functions defined on the set $W$. Meanwhile, $B(W)$ endowed with the sup metric $d(h, k)=\sup _{x \in W}|h x-k x|$ for all $h, k \in$ $B(W)$ is a complete metric space.

We consider the operators $f, T: B(W) \rightarrow B(W)$ given by

$$
\begin{aligned}
& f h(x)=\sup _{y \in D}\{p(x, y)+G(x, y, h(\tau(x, y)))\}, \quad x \in W, h \in B(W), \\
& T h(x)=\sup _{y \in D}\{q(x, y)+K(x, y, h(\tau(x, y)))\}, \quad x \in W, h \in B(W) .
\end{aligned}
$$

Suppose that the following conditions hold:

(A1) For any $h \in B(W)$, there exists $k \in B(W)$ such that

$$
f h(x)=T k(x), \quad x \in W .
$$

(A2) There exists $h \in B(W)$ such that

$$
f h(x)=\operatorname{Th}(x) \quad \text { implies } \quad T f h(x)=f T h(x), \quad x \in W .
$$

(A3) $p, q: W \times D \rightarrow \mathbb{R}$ and $G, K: W \times D \times \mathbb{R} \rightarrow \mathbb{R}$ are bounded.

(A4) $\xi(T h) \geq 0$ for some $h \in B(W)$ implies $\xi(f h) \geq 0$.

(A5) $|G(x, y, h(x))-G(x, y, k(x))| \leq \ln (1+M(h, k))$ where $h, k \in B(W), \xi(T h) \geq 0$, and $\xi(T k) \geq 0,(x, y) \in W \times D, t \in W$ and

$$
\begin{aligned}
M(h, k)= & \max \{d(\operatorname{Th}(t), T k(t)), d(\operatorname{Th}(t), f h(t)), d(T k(t), f k(t)), \\
& \left.\frac{1}{2}[d(\operatorname{Th}(t), f k(t))+d(T k(t), f h(t))]\right\} .
\end{aligned}
$$

(A6) If $\left\{h_{n}\right\}$ is a sequence in $B(W)$ such that $\xi\left(h_{n}\right) \geq 0$ for all $n \in \mathbb{N} \cup\{0\}$ and $h_{n} \rightarrow h^{*}$ as $n \rightarrow \infty$, then $\xi\left(h^{*}\right) \geq 0$.

(A7) There exists $h_{0} \in B(W)$ such that $\xi\left(T h_{0}\right) \geq 0$.

Theorem 5 Assume that conditions (A1)-(A7) are satisfied and $T(B(W))$ is a closed and bounded subspace of $B(W)$. Then the functional equations (4.1) and (4.2) have a unique common bounded solution in $W$.

Proof Let $\lambda$ be an arbitrary positive number and $x \in h_{1}, h_{2} \in B(W)$ such that $\xi\left(T h_{1}\right) \geq 0$ and $\xi\left(T h_{2}\right) \geq 0$. Then there exist $y_{1}, y_{2} \in D$ such that

$$
f h_{1}(x)<p\left(x, y_{1}\right)+G\left(x, y_{1}, h_{1}\left(\tau\left(x, y_{1}\right)\right)\right)+\lambda,
$$




$$
\begin{aligned}
& f h_{2}(x)<p\left(x, y_{2}\right)+G\left(x, y_{2}, h_{2}\left(\tau\left(x, y_{2}\right)\right)\right)+\lambda, \\
& f h_{1}(x) \geq p\left(x, y_{2}\right)+G\left(x, y_{2}, h_{1}\left(\tau\left(x, y_{2}\right)\right)\right), \\
& f h_{2}(x) \geq p\left(x, y_{1}\right)+G\left(x, y_{1}, h_{2}\left(\tau\left(x, y_{1}\right)\right)\right) .
\end{aligned}
$$

Next, by using (4.3) and (4.6), we have

$$
\begin{aligned}
f h_{1}(x)-f h_{2}(x) & <G\left(x, y_{1}, h_{1}\left(\tau\left(x, y_{1}\right)\right)\right)-G\left(x, y_{1}, h_{2}\left(\tau\left(x, y_{1}\right)\right)\right)+\lambda \\
& \leq\left|G\left(x, y_{1}, h_{1}\left(\tau\left(x, y_{1}\right)\right)\right)-G\left(x, y_{1}, h_{2}\left(\tau\left(x, y_{1}\right)\right)\right)\right|+\lambda \\
& \leq \ln \left(1+M\left(h_{1}, h_{2}\right)\right)+\lambda .
\end{aligned}
$$

Analogously, by using (4.4) and (4.5), we obtain

$$
f h_{2}(x)-f h_{1}(x)<\ln \left(1+M\left(h_{1}, h_{2}\right)\right)+\lambda .
$$

Therefore, from (4.7) and (4.8), we deduce

$$
\left|f h_{1}(x)-f h_{2}(x)\right|<\ln \left(1+M\left(h_{1}, h_{2}\right)\right)+\lambda
$$

or, equivalently,

$$
d\left(f h_{1}, f h_{2}\right) \leq \ln \left(1+M\left(h_{1}, h_{2}\right)\right)+\lambda .
$$

Since $\lambda>0$ is arbitrary, we get

$$
d\left(f h_{1}, f h_{2}\right) \leq \ln \left(1+M\left(h_{1}, h_{2}\right)\right) .
$$

Now, define $\alpha, \beta: B(W) \rightarrow[0, \infty)$ by

$$
\alpha(h)=\beta(h)= \begin{cases}1, & \text { if } \xi(h) \geq 0 \text { where } h \in B(W) \\ 0, & \text { otherwise }\end{cases}
$$

Also, define $\varphi, \eta:[0, \infty) \rightarrow[0, \infty)$ by $\varphi(t)=t$ and $\eta(t)=\ln (1+t)$. Therefore, using the last inequality, we have

$$
\alpha\left(T h_{1}\right) \beta\left(T h_{2}\right) \varphi\left(d\left(f h_{1}, f h_{2}\right)\right) \leq \eta\left(M\left(h_{1}, h_{2}\right)\right) .
$$

One easily shows that all the hypotheses of Corollary 1 are satisfied. Therefore $f$ and $T$ have a unique common fixed point, that is, the functional equations (4.1) and (4.2) have a unique bounded common solution.

Now, we give the following condition to use in the next theorem:

(A5') $|G(x, y, h(x))-G(x, y, k(x))| \leq \ln (1+N(h, k))$ where $h, k \in B(W), \xi(T h) \geq 0$, and $\xi(T k) \geq 0 ;$ and $(x, y) \in W \times D, t \in W$ and 


$$
\begin{aligned}
N(h, k)= & \max \left\{d(\operatorname{Th}(t), T k(t)), \frac{1}{2} d(\operatorname{Th}(t), f k(t)), d(T k(t), f h(t)),\right. \\
& \left.\frac{[1+d(\operatorname{Th}(t), f h(t))] d(T k(t), f k(t))}{1+d(\operatorname{Th}(t), T k(t))}\right\} .
\end{aligned}
$$

Theorem 6 Let all the conditions of Theorem 5 be fulfilled. If we write the condition (A5') instead of the condition (A5) in Theorem 5, then functional equations (4.1) and (4.2) have a unique common bounded solution in $W$.

Proof Following similar arguments to the proof of Theorem 5, one can easily show that all the hypotheses of Corollary 5 hold. Then the functional equations (4.1) and (4.2) have a unique bounded common solution.

\section{Competing interests}

The authors declare that they have no competing interests.

\section{Authors' contributions}

All authors contributed equally to the writing of this paper. All authors read and approved the final manuscript.

\section{Author details}

${ }^{1}$ Department of Mathematics, Gazi University, Ankara, Turkey. ${ }^{2}$ Department of Mathematics, College of Science, King Saud University, P.O. Box 2455, Riyadh, 11451, Saudi Arabia. ${ }^{3}$ Department of Mathematics and Computer Sciences, University of Palermo, Via Archirafi 34, Palermo, 90123, Italy.

\section{Acknowledgements}

The second author would like to extend his sincere appreciation to the Deanship of Scientific Research at King Saud University for its funding of this Prolific Research Group Project No. PRG-1436-10.

Received: 24 April 2015 Accepted: 21 August 2015 Published online: 15 September 2015

\section{References}

1. Banach, S: Sur les opérations dans les ensembles abstraits et leur application aux équations intégrales. Fundam. Math. 3, 133-181 (1922)

2. Khan, MS, Swaleh, M, Sessa, S: Fixed point theorems by altering distances between the points. Bull. Aust. Math. Soc. 30(1), 1-9 (1984)

3. Alber, Yl, Guerre-Delabriere, S: Principles of weakly contractive maps in Hilbert spaces. Oper. Theory, Adv. Appl. 98, 7-22 (1997)

4. Rhoades, BE: Some theorems on weakly contractive maps. Nonlinear Anal. 47(4), 2683-2693 (2001)

5. Dutta, PN, Choudhury, BS: A generalization of contraction principle in metric spaces. Fixed Point Theory Appl. 2008 $406368(2008)$

6. Yan, F, Su, Y, Feng, Q: A new contraction mapping principle in partially ordered metric spaces and applications to ordinary differential equations. Fixed Point Theory Appl. 2012, 152 (2012)

7. Samet, B, Vetro, C, Vetro, P: Fixed point theorems for $\alpha$ - $\psi$-contractive type mappings. Nonlinear Anal. 75, 2154-2165 (2012)

8. La Rosa, V, Vetro, P: Common fixed points for $\alpha-\psi-\varphi$-contractions in generalized metric spaces. Nonlinear Anal., Model. Control 19(1), 43-54 (2014)

9. Kumam, P, Vetro, C, Vetro, F: Fixed points for weak $\alpha-\psi$-contractions in partial metric spaces. Abstr. Appl. Anal. 2013, 986028 (2013)

10. Cho, SH, Bae, JS: Fixed points of weak $\alpha$-contraction type maps. Fixed Point Theory Appl. 2014, 175 (2014)

11. Salimi, $\mathrm{P}$, Vetro, $\mathrm{C}$, Vetro, $\mathrm{P}$ : Fixed point theorems for twisted $(\alpha, \beta)-\psi$-contractive type mappings and applications. Filomat 27(4), 605-615 (2013)

12. Alizadeh, S, Moradlou, F, Salimi, P: Some fixed point results for $(\alpha, \beta)-(\psi, \varphi)$-contractive mappings. Filomat 28(3), 635-647 (2014)

13. Moradlou, F, Salimi, P, Vetro, P: Fixed point results for $r-(\eta, \xi, \psi)$-contractive mappings of type (I), (II) and (III). Filomat 27(2), 403-410 (2013)

14. Su, Y: Contraction mapping principle with generalized altering distance function in ordered metric spaces and applications to ordinary differential equations. Fixed Point Theory Appl. 2014, 227 (2014)

15. Jungck, G, Rhoades, BE: Fixed points for set valued functions without continuity. Indian J. Pure Appl. Math. 29 227-238 (1998)

16. Kirk, WA, Srinavasan, PS, Veeramani, P: Fixed points for mapping satisfying cyclical contractive conditions. Fixed Point Theory 4, 79-89 (2003)

17. Pacurar, M, Rus, IA: Fixed point theory for cyclic $\phi$-contractions. Nonlinear Anal. 72, 1181-1187 (2010)

18. Agarwal, RP, Alghamdi, MA, Shahzad, N: Fixed point theory for cyclic generalized contractions in partial metric spaces. Fixed Point Theory Appl. 2012, 40 (2012)

19. Karapınar, E, Shobkolaei, N, Sedghi, S, Vaezpour, SM: A common fixed point theorem for cyclic operators on partial metric spaces. Filomat 26(2), 407-414 (2012) 
20. Abbas, M, Ali, B, Vetro, C: A Suzuki type fixed point theorem for a generalized multivalued mapping on partial Hausdorff metric spaces. Topol. Appl. 160(3), 553-563 (2013)

21. Imdad, M, Chauhan, S, Kadelburg, Z, Vetro, C: Fixed point theorems for non-self mappings in symmetric spaces under phi-weak contractive conditions and an application to functional equations in dynamic programming. Appl. Math. Comput. 227, 469-479 (2014)

22. Aydi, H, Abbas, M, Vetro, C: Common fixed points for multivalued generalized contractions on partial metric spaces. Rev. R. Acad. Cienc. Exactas Fís. Nat., Ser. A Mat. 108(2), 483-501 (2014)

23. Bellman, R, Lee, ES: Functional equations in dynamic programming. Aequ. Math. 17, 1-18 (1978)

24. Bhakta, TC, Mitra, S: Some existence theorems for functional equations arising in dynamic programming. J. Math. Anal. Appl. 98, 348-362 (1984)

Submit your manuscript to a SpringerOpen ${ }^{\circ}$ journal and benefit from:

- Convenient online submission

Rigorous peer review

- Immediate publication on acceptance

- Open access: articles freely available online

- High visibility within the field

- Retaining the copyright to your article 